\title{
OBSTÁCULOS Y ESTÍMULOS A LA INTEGRACIÓN DE LAS REGIONES ATLÁNTICAS REGRESIVAS
}

\author{
Paz Benito del Pozo \\ Departamento de Geografía \\ Universidad de León
}

\section{RESUMEN}

En este artículo se indaga sobre la situación de una región atlántica marcada por los caracteres propios de las regiones periféricas, Asturias, y sobre las acciones de reactivación económica y dinamización territorial previstas por el Gobierno regional con el objetivo estratégico de modernizar las estructuras productivas de la comunidad autónoma y reforzar su integración a escala internacional para situarla, de manera estable, en el mapa de las regiones europeas que progresan. La tesis mantenida es que tal empeño encuentra grandes obstáculos por el peso, fundamentalmente, de factores internos, entre los que no están ausentes elementos territoriales.

Palabras clave: Territorio, políticas de reactivación, Asturias, regiones periféricas, espacio atlántico.

\section{SUMMARY}

This article deals with the situation of an Atlantic region marked by the characteristic features of the peripheral regions, such as Asturias. It also investigates the economic reactivation and territorial dynamism actions planned by the regional Government so as to favour its integration at an international level and to situate it, steadily, in the map of the European regions developing. It is held the thesis that such effort meets with great obstacles mainly due to the weight of internal factors, among which territorial elements are not absent.

Key words: Territory, Reactivation policies, Asturias, peripheral regions, Atlantic space.

\section{Introducción}

Desde comienzo de los años noventa son múltiples y variadas las voces que se han alzado en favor de la necesidad de impulsar el crecimiento y la convergencia de las regiones europeas periféricas, es decir, de aquellas más alejadas de la Gran Dorsal, habida cuenta 
del retraso y los riesgos de marginalidad que ofrecían los espacios comunitarios englobados dentro de los denominados Finisterres y Sures reflejados en el mapa europeo elaborado por GIP-RECLUS en 1989. Esta situación, agudizada por la evidente tendencia hacia el desarrollo horizontal del continente, hacia el centro de la vieja Europa, por efecto de la eliminación de fronteras en la CE, la unificación alemana, la incorporación de Austria a la Unión Europea y la apertura a los países del Este, venía a ser la confirmación de una Europa de distintas velocidades, de desarrollo desigual y fuertes desequilibrios internos.

Por lo que respecta a España, las tendencias apuntaban en los albores de esa década hacia una evolución contrastada de las distintas áreas del país en favor del eje mediterráneo y el eje del Ebro que, tal y como se verifica en la actualidad, aparecen ya incorporadas al mapa de los espacios con mayor dinamismo y posibilidades de integración, mientras que se confirma la existencia de zonas relegadas a una situación de periferia o progresiva periferización como es el caso de Galicia y la Cornisa Cantábrica. Para este tipo de regiones la convergencia con las regiones que ganan no es sencilla y comporta, al decir de los expertos, actuaciones de envergadura no sólo en materia de infraestructuras sino también en la aplicación de políticas orientadas a aprovechar las oportunidades que ofrecen el desarrollo de las nuevas tecnologías y las ventajas que pueden derivarse de la mayor libertad para la localización de las inversiones (Cuadrado Roura, J.R.; García Greciano, B., 1995).

En este contexto hay que situar la problemática y la búsqueda de soluciones para Asturias, una pequeña región de $10.603 \mathrm{~km}^{2}$ de superficie (el $2,1 \%$ del total nacional) y 1.081.834 habitantes en 1998, incluida en el dominio de la Cornisa Cantábrica y dentro del ámbito de los Finisterres europeos. Especializada desde las primeras etapas de la industrialización española en producciones básicas — carbón y fabricación de hierro y acerofue durante décadas una región próspera que suministraba materia prima y productos intermedios a la industria transformadora nacional, lo que permitió el desarrollo de una sociedad moderna con un notable nivel de renta en contraste con otras regiones españolas, más atrasadas y de eminente carácter rural.

Su evolución reciente la sitúa, empero, entre las regiones españolas y europeas en declive, ofreciendo en la actualidad un cuadro de indicadores básicos que permite afirmar su condición

1. «Finisterres».

2. «Sures».

3. Extensión de la dorsal al sur.

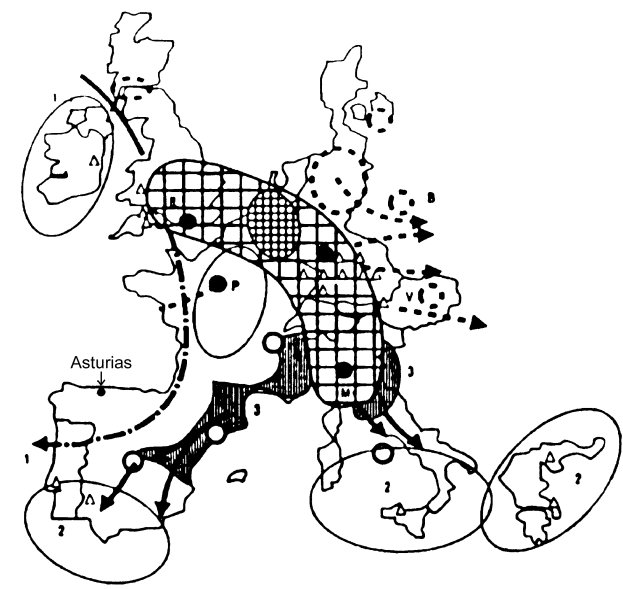

FIGURA 1. Situación de Asturias respecto a los ejes de desarrollo en Europa. 
de región perdedora, a pesar de los esfuerzos de la Administración central y del Gobierno regional por reactivar su economía, en particular la industria, y en contraste con otras regiones cantábricas españolas, entre las que destaca el País Vasco, que han aplicado estrategias y políticas de éxito frente a la crisis de sus respectivas economías (Bosque y Méndez, 1995).

\section{Características y magnitud de la crisis asturiana}

Aun cuando Asturias partía a principios del siglo XX de una posición de ventaja para situarse entre las regiones más prósperas del país (en 1955 era una de las regiones españolas con mayor renta per capita), en competencia sobre todo con la industria vasca, su nivel de competitividad fue decreciendo con los años, tal y como demuestra el análisis de la evolución de los indicadores de productividad, empleo y renta (De la Fuente, 1998). En efecto, el nivel total de empleo en Asturias ha caído casi sin interrupción desde 1960, de forma que en 1998 era la tercera región con mayor tasa de paro de España $(19,07)$ sólo por detrás de Extremadura y Andalucía. Este hecho se ha acompañado de un claro retroceso en el nivel de vida relativo (renta per capita) de sus habitantes: del quinto puesto por este indicador en 1955 pasó en 1991 al puesto 11 en el ranking nacional, situándose en 1999 en el duodécimo lugar.

Desde el punto de vista demográfico la región pierde población desde 1986, hecho al que se añaden otros tres rasgos definitorios: la concentración en la Zona Central (casi el $80 \%$ del total), el despoblamiento (más de 14 municipios sobre un total de 78 no alcanzan los 10 habitantes por $\mathrm{Km}^{2}$ y en las zonas rurales abundan los pueblos abandonados) y su acusado grado de envejecimiento, debido sobre todo al fuerte descenso de la natalidad $(0,7$ hijos por mujer) y a una cierta estabilidad de la mortalidad. Esta situación incide de forma negativa en el mercado de trabajo, pues la población activa y ocupada disminuye, lo que se traduce en un tasas de actividad y de ocupación decrecientes en el período 1990-1998, muy por debajo ambas de la media nacional para el último año del período (Cuadro 1).

En el orden económico, un rasgo distintivo de la industria asturiana, apuntado con anterioridad, es su estructura productiva fuertemente especializada en materias básicas (carbón,

Cuadro 1

INDICADORES DEL MERCADO DE TRABAJO EN ASTURIAS Y ESPAÑA, 1990-1998 (MILES)

\begin{tabular}{|l|c|c|c|c|c|c|}
\hline & \multicolumn{5}{|c|}{ Asturias } & España \\
\cline { 2 - 7 } & $\mathbf{1 9 9 0}$ & $\mathbf{1 9 9 2}$ & $\mathbf{1 9 9 4}$ & $\mathbf{1 9 9 6}$ & $\mathbf{1 9 9 8}$ & $\mathbf{1 9 9 8}$ \\
\hline Población >16 años & 912,1 & 925,9 & 928,5 & 917,1 & 918,1 & 32.53 \\
& & & & & & 4,1 \\
\hline Población activa & 429,6 & 413,3 & 396,9 & 399,4 & 389,4 & 16.26 \\
& & & & & & 5,2 \\
\hline Tasa de actividad (\%) & 47,1 & 44,6 & 42,8 & 43,6 & 42,42 & 49,99 \\
\hline Población ocupada & 355,2 & 342,1 & 307,6 & 315,8 & 315,15 & 13.20 \\
& & & & & & 4,9 \\
\hline Tasa de ocupación & 38,9 & 36,9 & 33,1 & 34,4 & 34,33 & 40,59 \\
\hline Parados & 74,4 & 71,2 & 89,4 & 83,6 & 74,28 & 3.06 \\
& & & & & & 0,4 \\
\hline Tasa de paro & 17,3 & 17,2 & 22,5 & 20,25 & 19,07 & 18,82 \\
\hline
\end{tabular}

FUENTE: Plan de Desarrollo Regional 2000-2003. 
hierro y acero, zinc, cobre, aluminio) muy exigentes en mano de obra y concentradas espacialmente en el Área Central de la región, cerca de los yacimientos hulleros en la etapa correspondiente a la primera oleada industrializadora y más tarde localizadas en relación estrecha con los puertos de la franja litoral. Un segundo elemento a considerar es el protagonismo en los sectores industriales clave de un empresariado no asturiano con fuertes intereses fuera de la región, que en los momentos en que se hace más necesario reestructurar y modernizar las empresas abandonan los negocios en Asturias y es el Estado el que asume, por la vía de la nacionalización, las pérdidas y el futuro de las actividades en riesgo de extinción.

Por el mecanismo descrito el grueso de la industria asturiana pasó a estar, entre los años 60 y 70 del siglo XX, en manos del Estado, primer empresario de la región y titular, entre otras, de las dos grandes empresas en las que se apoyará la industria asturiana: la compañía minera Hunosa y la empresa siderúrgica Ensidesa, cada una de las cuales llegó a dar ocupación a más de 20.000 trabajadores, concentrando entre las dos el 86\% del empleo industrial público regional en el año 1980. La importancia relativa de estas empresas apenas sufrirá mengua en años sucesivos pese a la fuerte contracción del empleo total industrial público con pérdidas máximas en 1995, año éste en que la crisis se manifiesta con suma agudeza (Cuadro 2) y tras el que se abrirá un imparable proceso de privatizaciones que dará como resultado la venta, entre otras, de Ensidesa a un grupo extranjero y su conversión en una nueva compañía, Aceralia (Benito del Pozo, 2000a).

Cuadro 2

EVOLUCIÓN DE LAS PLANTILLAS DE LAS EMPRESAS PÚBLICAS ASTURIANAS (1980-1995)

\begin{tabular}{|c|c|c|c|c|c|c|c|}
\hline & 1980 & 1982 & 1984 & 1986 & 1988 & 1990 & 1995 \\
\hline $\begin{array}{l}\text { Metál. Básicas } \\
\text { Ensidesa } \\
\text { Inespal }\end{array}$ & $\begin{array}{c}23.433 \\
984\end{array}$ & $\begin{array}{c}21.015 \\
904\end{array}$ & $\begin{array}{c}20.607 \\
909\end{array}$ & $\begin{array}{c}17.875 \\
730\end{array}$ & $\begin{array}{c}16.088 \\
657\end{array}$ & $\begin{array}{c}14.550 \\
628\end{array}$ & $\begin{array}{c}9.646 \\
527\end{array}$ \\
\hline $\begin{array}{l}\text { Trans. Metálicos } \\
\text { Metalsa } \\
\text { Perfrisa } \\
\text { ENSB } \\
\text { Tetracero }\end{array}$ & $\begin{array}{c}8 \\
317 \\
2.123 \\
-\end{array}$ & $\begin{array}{c}45 \\
321 \\
2.119 \\
-\end{array}$ & $\begin{array}{c}139 \\
311 \\
1.876 \\
-\end{array}$ & $\begin{array}{c}264 \\
297 \\
1.809 \\
94\end{array}$ & $\begin{array}{c}281 \\
293 \\
1.447 \\
111\end{array}$ & $\begin{array}{c}296 \\
273 \\
1.263 \\
116\end{array}$ & $\begin{array}{c}285 \\
245 \\
875 \\
46\end{array}$ \\
\hline $\begin{array}{l}\text { Const. Naval } \\
\text { Juliana Constructora } \\
\text { Químicas } \\
\text { Enfersa }\end{array}$ & $\begin{array}{l}1.665 \\
443\end{array}$ & $\begin{array}{c}1.530 \\
438\end{array}$ & $\begin{array}{c}1.451 \\
421\end{array}$ & $\begin{array}{l}1.235 \\
409\end{array}$ & $\begin{array}{l}995 \\
335\end{array}$ & $\begin{array}{l}786 \\
-\end{array}$ & $\begin{array}{l}720 \\
-\end{array}$ \\
\hline $\begin{array}{l}\text { Minería } \\
\text { Hunosa } \\
\text { Figaredo } \\
\text { Aboño } \\
\text { Domi }\end{array}$ & $\begin{array}{c}22.150 \\
1.374 \\
204 \\
224\end{array}$ & $\begin{array}{c}21.149 \\
1.417 \\
182 \\
-\end{array}$ & $\begin{array}{c}21.018 \\
1.460 \\
162 \\
346\end{array}$ & $\begin{array}{c}20.470 \\
1.441 \\
154 \\
219\end{array}$ & $\begin{array}{c}19.307 \\
1.386 \\
146 \\
27\end{array}$ & $\begin{array}{c}18.250 \\
1.320 \\
- \\
-\end{array}$ & $\begin{array}{c}10.200 \\
775 \\
- \\
-\end{array}$ \\
\hline $\begin{array}{l}\text { Eléctricas } \\
\text { Eléc. Viesgo }\end{array}$ & - & - & - & - & - & - & 320 \\
\hline TOTAL & 52.925 & 49.120 & 48.700 & 44.997 & 41.073 & 37.482 & 23.319 \\
\hline
\end{tabular}

Fuente: Elaboración propia con datos de UGT-Asturias. 
Las dificultades de la economía asturiana para diversificar su tejido industrial y modernizarse al ritmo marcado por las exigencias del mercado internacional quedaron patentes tras la crisis mundial de 1973, de muy negativos efectos sobre la industria regional, que a partir de ese año entró en un proceso de deterioro progresivo de claro componente estructural que la configura como una región en declive, análoga a otras regiones europeas como País de Gales(Reino Unido), Ruhr (Alemania) Nort-Pas de Calais (Francia) o Valonia (Bélgica) (Benito del Pozo, 1995).

Desde esos años Asturias se resintió cada vez con mayor intensidad de la pérdida de posiciones en el mercado mundial de sus producciones industriales básicas, sometidas a duros ajustes a la baja con la consiguiente reducción de capacidades (cierre de empresas)y destrucción de empleo. Sólo en las empresas industriales públicas se perdieron entre 1980 y 1995 casi 30.000 puestos de trabajo (56\% del total al principio del periodo), lo que da idea de la magnitud de la crisis (Cuadro 2).

Por su parte, las reconversiones sucesivas de los sectores hullero, siderometalúrgico, construcción naval y química pesada no se acompañaron de la génesis de nuevo tejido productivo ni de la implantación de actividades alternativas en los sectores emergentes: nuevas tecnologías, servicios especializados, turismo de calidad, etcétera. En consecuencia, el sector industrial ha retrocedido significativamente en el período 1990-1997 y con mayor intensidad que en el conjunto de España.

Cuadro 3

PORCENTAJE DEL VAB C.F. SOBRE CADA SECTOR DE LA PRODUCCIÓN. ESPAÑA Y ASTURIAS, 1990-1997

\begin{tabular}{|l|c|c|c|c|c|c|c|c|}
\hline \multirow{2}{*}{ Año } & \multicolumn{2}{|c|}{ Agricultura y Pesca } & \multicolumn{2}{|c|}{ Industria } & \multicolumn{2}{c|}{ Construcción } & \multicolumn{2}{c|}{ Servicios } \\
\cline { 2 - 9 } & España & Asturias & España & Asturias & España & Asturias & España & Asturias \\
\hline 1990 & 5,2 & 3,7 & 25,9 & 35,6 & 9,7 & 9,4 & 59,2 & 51,4 \\
1997 & 4,95 & 4,11 & 21,64 & 27,68 & 7,89 & 7,14 & 65,52 & 61,07 \\
\hline
\end{tabular}

FUENTE: Plan de Desarrollo Regional 2000-2003.

Desde el punto de vista de las causas o factores internos a la propia región que de manera más evidente explican la crisis de la misma, los estudios y trabajos publicados (Castells, 1994; Vázquez, 1994) coinciden en destacar los siguientes factores endógenos:

- Excesiva especialización en sectores maduros o de demanda débil.

- Escasez de pequeñas y medianas empresas innovadoras.

- Hegemonía hasta fecha reciente de pocas y muy grandes empresas públicas.

- Escasa propensión de las empresas hacia la cooperación y las alianzas estratégicas.

- Deficientes infraestructuras de transporte y comunicaciones.

- Acusado deterioro medioambiental de los espacios urbano-industriales.

- Actitudes sindicales tradicionales y conservadoras.

- Débil conexión entre universidad y empresas.

- Ineficaz gestión política de la crisis.

- Mala imagen exterior de la región.

La situación descrita coloca a Asturias entre las regiones de tradición industrial en declive que mayores dificultades está teniendo dentro del grupo de regiones periféricas de 
la Unión Europea (reunidas en lo que se conoce como Arco Atlántico) para superar la crisis, pues a los problemas económicos hay que añadir, en opinión de Vázquez y Benavides (1992: 168), «la insuficiencia e inadecuación de las infraestructuras de todo tipo, el deterioro ambiental, el bajo nivel de desarrollo de los servicios, y en particular de los destinados a las empresas, el retraso tecnológico, las carencias de suelo industria, las débiles estructuras comerciales y de distribución y la falta de espíritu cooperativo entre las empresas», sin olvidar las inercias sociales que impiden la ruptura con el modelo económico tradicional y la desatinada gestión política de la crisis.

$\mathrm{Si}$, además, tomamos en consideración la evolución de los principales indicadores de renta resulta que el PIB per capita asturiano se ha reducido 14,4 puntos porcentuales desde 1980, pasando de 107,9\% sobre la media de España al 93,5\% de la misma en 1996; con respecto a la Unión Europea, la pérdida en dicho período se cifra en 2,5 puntos porcentuales (cuadro 4). Es más, según datos del INE para 1998 el crecimiento del PIB real de Asturias fue el más bajo del país, 2,46\% frente al 4,60\% de España, lo que supone que Asturias fue la única comunidad autónoma cuyo crecimiento económico fue inferior a la media de la Unión Europea, cifrado en 2,9\% (figura 2).

Cuadro 4

PIB POR HABITANTE DE ASTURIAS, ESPAÑA Y LA UNIÓN EUROPEA

\begin{tabular}{|c|c|c|c|}
\hline & PPS/hab. & Indice España=100 & Índice UE=100 \\
\hline 1980 & 5.486 & 107,9 & 76,1 \\
1985 & 7.703 & 103,9 & 73,3 \\
1990 & 10.395 & 92,2 & 69,4 \\
1996 & 13.326 & 93,5 & 73,6 \\
\hline
\end{tabular}

FUENTE: INE, Contabilidad Regional de España.

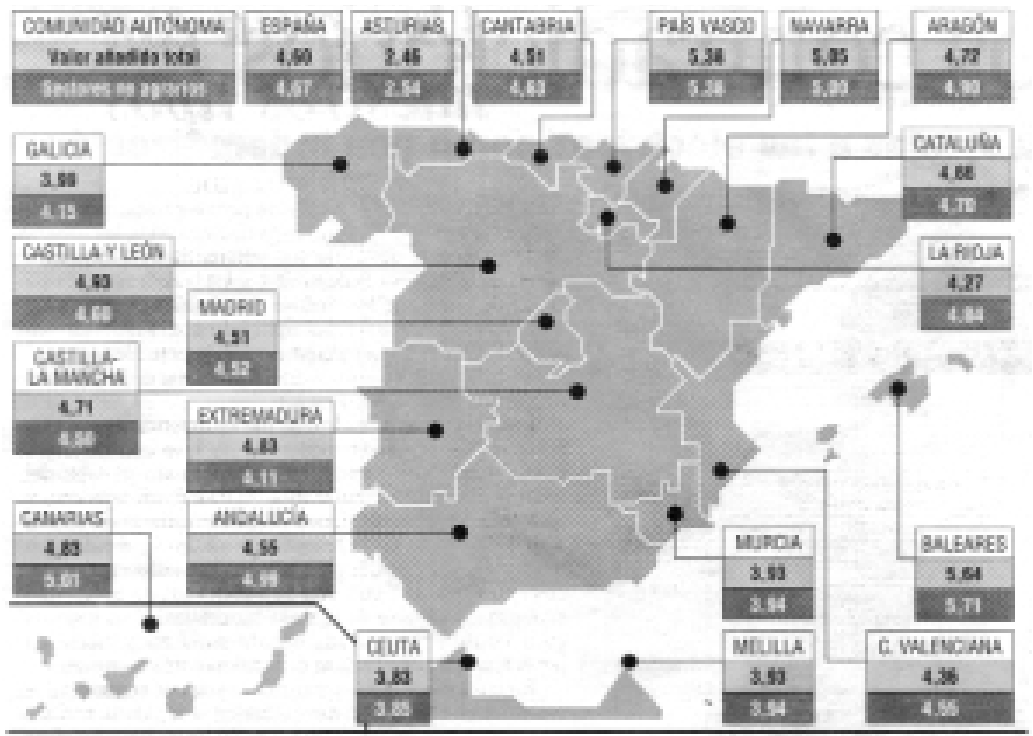

FIGURA 2: Crecimiento real del PIB por comunidades autónomas en 1998. 
Todo lo expuesto se traduce en una débil convergencia con los espacios y las economías nacional y comunitaria y en un proceso muy lento de transición hacia unas estructuras productivas modernas y competitivas que permitan que la región revierta el declive y se integre en escenarios regionales más prósperos aún cuando siga formando parte de un espacio alejado de los ejes más dinámicos de la UE (Del Castillo, 1992; Villaverde, 1994; Vázquez, 1994).

\section{El modelo espacial de la crisis}

El modelo territorial que se esboza en las primeras etapas del proceso de industrialización regional y que se consolida en los años 50 y 60 del presente siglo, ha dado origen a una Zona Central fuertemente urbanizada, en la que se concentra cerca del $80 \%$ de la población, los recursos y las infraestructuras básicas, así como la industria y las actividades de servicios, mientras las zonas Occidental y Oriental, de marcado carácter rural y dependientes de las actividades agropecuarias, se configuran como periferia a todos los efectos, resultando un modelo territorial fuertemente desequilibrado (Castells, 1994).

En este sentido cabe destacar la poca importancia de los fenómenos de difusión industrial, de los que en principio se podía esperar un efecto motriz sobre las economías locales ajenas al proceso histórico de industrialización. La tendencia dominante es, por el contrario, hacia una mayor concentración de la industria y los servicios en la Zona Central, fenómeno que a escala regional perpetúa la polarización tradicional de actividades industriales y agudiza los contrastes económicos entre los municipios y comarcas del solar regional (Colina, 1995; Castells, 1994; Benito del Pozo, 1995).

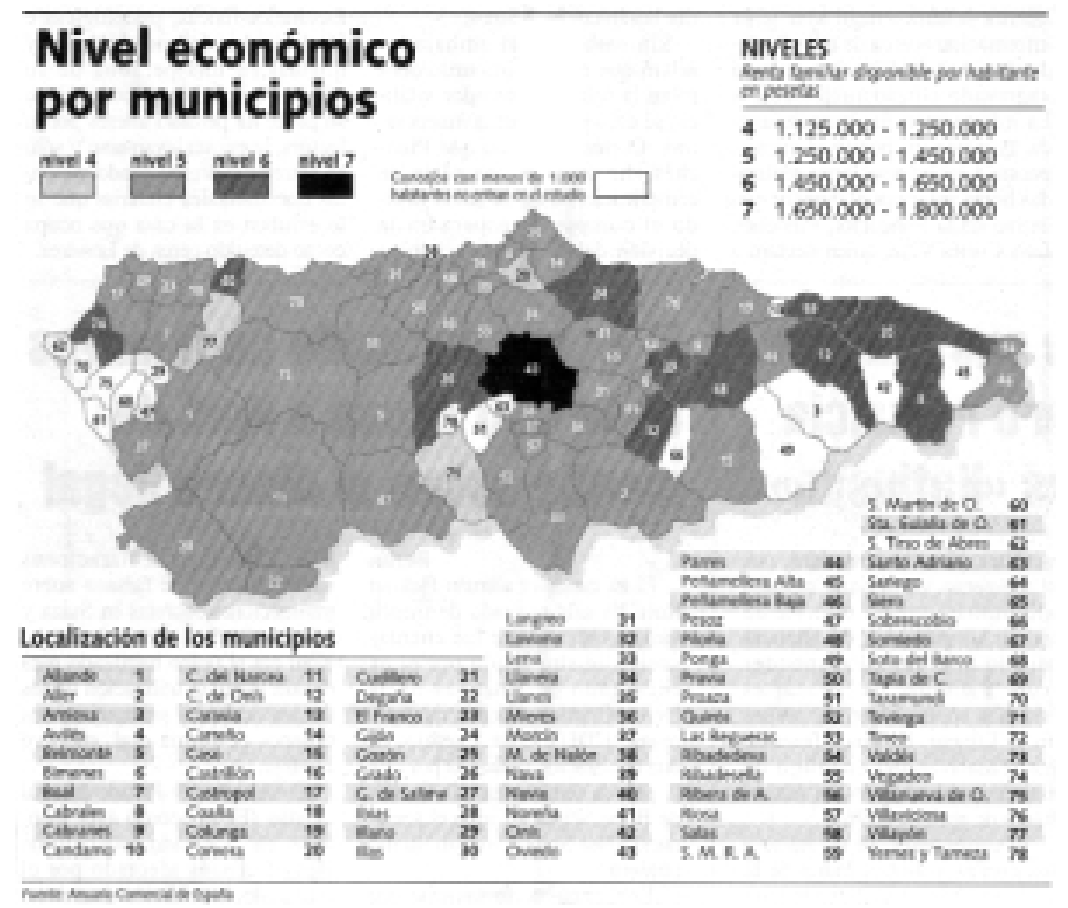

FIGURA 3: Nivel económico por municipios en 1998. 
Asimismo, el área urbano-industrial desarrollada dentro de la Zona Central y vertebrada por Oviedo, Gijón, Avilés, Mieres y Langreo, lejos de ser un espacio homogéneo, manifiesta profundas tensiones internas como consecuencia del desigual impacto de la crisis y de la desindustrialización. Las primeras etapas del proceso de industrialización tuvieron como escenario privilegiado la cuenca central hullera, con Mieres y Langreo a la cabeza de una actividad minero-siderúrgica pujante que permitió el crecimiento de ambas ciudades y también, por complementariedad funcional, la consolidación de Oviedo como centro regional de servicios. Avilés y Gijón, en razón de su emplazamiento litoral, se beneficiaron de la prosperidad irradiada desde las cuencas mineras, en tanto que canalizadoras de los tráficos portuarios generados por la actividad hullera y siderúrgica y como polos de una incipiente industria transformadora.

Las estrategias de localización de la industria pesada que se imponen a partir de los años sesenta del presente siglo, en particular de la siderurgia, explican el traslado de las fábricas de Mieres y Langreo al litoral. Este hecho será determinante en la configuración del actual espacio industrial asturiano, pues como consecuencia del mismo nacen los dos complejos industriales portuarios de Avilés y Gijón, al tiempo que marca el inicio del declive de las cuencas mineras del Caudal y del Nalón.

La política desarrollista de los años 60 y la planificación indicativa, copiada del modelo francés de polos de desarrollo, favorecieron la implantación de industrias de tipo manufacturero (alimentación, madera y muebles, artes gráficas, cerámica y vidrio, textil) agrupadas en polígonos industriales que jalonan el espacio que separa los complejos portuarios de las zonas mineras del interior, en particular el entorno de Lugones. Si a esto sumamos los corredores industriales que comienzan a dibujarse entre Oviedo y Pola de Siero y entre Oviedo y Gijón, se completa el mapa de elementos que integran el espacio industrial del Área Central en la etapa que deja paso a las acciones de reestructuración productiva.

\section{Efectos territoriales del declive}

Sobre el conjunto de la región y sus diferentes zonas económicas y espacios funcionales, el declive ha incidido de forma desigual y muestra diversos escenarios contrastados:

\section{A) Las cuencas mineras del Caudal y Nalón}

Aquí el declive y los fenómenos que le acompañan (recesión económica generalizada, descenso del nivel de renta de la población, alto índice de paro, emigración, baldíos y ruinas industriales, degradación ambiental y urbana...) están estrechamente ligados al desmantelamiento siderúrgico en los años 80 y a la reconversión minera y los avatares de la empresa pública Hunosa en los años 90. El despoblamiento, el desempleo, la escasez de inversiones y la falta de oportunidades para los que no han emigrado han sumido a la comarca en una difícil situación ante la que han resultado poco eficaces las políticas reindustrializadoras: ZUR, PAUR y ZPE (Pascual, 1993).

\section{B) Las comarcas siderúrgicas (Gijón y Avilés)}

En este espacio industrial los ajustes a la baja en los sectores naval y siderometalúrgico apenas han sido compensados por la implantación de empresas como la multinacional Du Pont o el fortalecimiento del tejido de pequeñas y medianas empresas (pymes). Sin 
embargo, en el entorno de Lugones, aprovechando la amplia oferta de suelo, las buenas comunicaciones y una mayor calidad medioambiental, se detecta un prometedor dinamismo que tiene expresión en la colmatación de polígonos industriales y la densificación de los corredores industriales. Otro hecho que puede contribuir a la reactivación de este espacio es la reciente privatización de la empresa Ensidesa, hoy titulada Aceralia y participada de manera mayoritaria por capital luxemburgués (Grupo Arbet) (Benito del Pozo, 2000a).

\section{C) Las ciudades del área metropolitana}

A causa de la crisis industrial también se han alterado la jerarquía y funcionalidad de las ciudades del Área Central. Así, Gijón y Oviedo han reforzado su hegemonía urbana y productiva, la primera con un peso importante de la industria en equilibrio con el sector servicios, la segunda confirmando su especialización terciaria. Por su parte, Avilés, Mieres y Langreo, las más castigadas por las sucesivas reconversiones, además de sufrir importantes pérdidas de población y destrucción de empleo, no parece posible que puedan cifrar sus estrategias para superar el declive en un nuevo tirón de la industria, debiendo buscar alternativas en otras funciones que las acerquen, en términos de integración y competitividad, a las dos primeras ciudades de la región.

\section{D) Las comarcas no industrializadas}

Se trata de un amplio espacio regional que comprende las comarcas Oriental y Occidental de carácter rural y con problemas de despoblación, envejecimiento de la población, débil integración con el centro de la región (aislamiento y escasa accesibilidad) y atonía productiva. En la comarca Oriental el turismo ha estimulado en los últimos años el pulso económico de los municipios que lideran esta actividad alternativa (sobre todo en Llanes) permitiendo frenar la sangría demográfica, aunque se mantienen los rasgos de periferia.

Con carácter general podemos afirmar que el declive ha agudizado los desequilibrios intrarregionales y la desarticulación territorial, lo que frena su cohesión económica y territorial. Además, el declive ha exacerbado la competencia entre las ciudades más importantes, algunas de ellas, Avilés y Gijón, han acudido a la planificación estratégica para buscar soluciones a su futuro, si bien la falta de compromiso efectivo de los principales agentes implicados (políticos, económicos y sociales) ha restado eficacia a este instrumento en ambas ciudades (Benito del Pozo, 1997).

\section{Estrategias y acciones de reactivación para la región}

Según se recoge en el documento más importante sobre las líneas de actuación en materia de desarrollo regional, el denominado Plan de Desarrollo Regional de Asturias 20002006, la estrategia conjunta de los Gobiernos central y asturiano para superar el declive y situar a la región entre aquellas que progresan se orienta en una dirección: mejorar la competitividad de forma que Asturias logre un crecimiento económico sólido y sostenible que haga posible la convergencia con las regiones españolas y europeas más dinámicas.

En relación con esta estrategia general, los responsables públicos se marcan tres grandes prioridades u objetivos: 
A) Promover los factores esenciales de la competitividad regional. Aquí se considera necesario actuar sobre cinco factores u objetivos instrumentales determinantes para el crecimiento de la productividad de la región:

- Mejorar la dotación y red de infraestructuras básicas, sobre todo de transporte y comunicaciones.

- Promover el empleo estable y las políticas de formación.

- Potenciar la innovación y desarrollo tecnológico.

- Promover la implantación de nuevas tecnologías de información.

- Incentivar medidas de apoyo a las pequeñas y medianas empresas (pymes).

B) Desarrollar una organización territorial equilibrada. El objetivo desde esta perspectiva es reducir las disparidades y desajustes territoriales buscando un grado de convergencia aceptable entre las distintas comarcas a través de una ordenación del territorio equilibrada. Las acciones se orientan en cinco direcciones:

- Fortalecer el conjunto de ciudades del Área Central, en torno a Oviedo, Gijón, Avilés, Mieres y Langreo incrementando su interdependencia para que actúen como motor del desarrollo regional. El Plan Intermodal de Transporte de Viajeros y la creación de una Zona de Actividades Logísticas son los elementos clave.

- Potenciar la relación del Área Central con los espacios periféricos regionales, a través fundamentalmente de actuaciones en la red viaria y de las telecomunicaciones.

- Impulsar planes estratégicos comarcales en las zonas periféricas que permitan vertebrar amplias zonas rurales y llevar a la práctica políticas de descentralización y transferencia de funciones a las entidades locales.

- Reforzar la dotación de equipamientos educativos y sociales en las zonas Oriental y Occidental de la región.

— Fomentar el desarrollo sostenible y equilibrado del turismo y del medio rural.

C) Mejora del entorno y la calidad de vida. Los factores que más directamente inciden en el desarrollo armonioso del entorno y mejora de la calidad de vida y sobre los que propone actuar el PDR asturiano, son los siguientes:

- Conservación y mejora del entorno medioambiental, concentrando los esfuerzos en mantener la vitalidad y diversidad de las especies y de los ecosistemas naturales así como una adecuada gestión del agua.

- Promoción y ampliación de la oferta cultural.

- Igualdad de oportunidades, factor decisivo en la construcción de una sociedad más integrada y solidaria.

La articulación territorial a escala suprarregional se resuelve desde las instancias oficiales mediante la propuesta de invertir en la creación de grandes infraestructuras de transporte viarias y ferroviarias: así la autovía del Cantábrico (eje de sentido Este-Oeste) y la variante ferroviaria de Pajares (eje Norte-Sur), redes transeuropeas de transporte, son elementos de articulación de la Unión Europea, de un Estado miembro y de una región, hecho que avala la necesidad y prioridad que debe darse a estas actuaciones en razón de su papel equilibrador de las disparidades interregionales. 
Además del PDR cabe destacar un segundo esfuerzo institucional a favor de la mejora de las condiciones de la región: el Pacto Institucional por el Empleo 2000-2003 suscrito entre el Gobierno regional y los agentes sociales con mayor representatividad en Asturias (UGT, CC OO y la Federación Asturiana de Empresarios) en torno a una estrategia conjunta por el empleo y con una cuantía global del presupuesto regional de 87.440 millones de pesetas. Dicho documento recoge un conjunto de actuaciones y medidas con el fin de ordenar y desarrollar las políticas activas con un enfoque integral que se articula en cuatro ejes de desarrollo:

- Industria: se apuesta por la industria como elemento generador de riqueza y se propone concentrar las acciones en tres líneas: desarrollo y modernización de infraestructuras, promoción industrial e innovación empresarial. A este eje se destina la mayor partida presupuestaria del Pacto, 46.780 millones de pesetas que representan el 53,5\% del total aprobado.

- Empleo: es el segundo pilar de este acuerdo institucional y su objetivo fundamental es la promoción de empleo estable y la mejora de la competitividad empresarial así como el recurso al desarrollo local para la creación de empleo. Este eje tiene asignados 23.440 millones de pesetas, el 26,8\% del presupuesto del Pacto.

- Formación: se trata de dar respuesta a las necesidades de la formación ocupacional, apoyar programas en esta línea, proyectos integrales e innovadores, acciones de integración e inserción y acciones de información, sin olvidar la formación continua para trabajadores y la creación de estructuras de apoyo a programas formativos. En total a tales fines se destinan 16.620 millones de pesetas, el $19 \%$ del total.

- Seguridad y salud laboral: a este eje se destinan 600 millones de pesetas, el 0,7\% del Pacto, para atender aspectos relativos a la formación y sensibilización entre empresarios y empleados en materia de prevención de riesgos laborales, de acuerdo con la Ley de Prevención de 1997.

\section{Conclusiones}

El declive que lastra a la región de Asturias, encuadrada dentro de las regiones Objetivo $\mathrm{n}^{\mathrm{o}} 1$ de la Unión Europea a pesar de su carácter eminentemente industrial, hace difícil la creación de condiciones que permitan revertir el proceso de recesión y situarla entre las regiones que ganan. Los factores más importantes que explican este hecho se han analizado aquí. También se han expuesto las acciones que el Gobierno asturiano, con el apoyo de la Administración central en el caso del $P D R$ y de los principales agentes sociales en el caso del Pacto por el Empleo, está dispuesto a ejecutar para mejorar la competitividad de la región. En conjunto la estrategia parece acertada pero hasta la fecha los resultados no son evaluables a falta de datos sobre la inversión real ejecutada en cada programa y línea de actuación seguidas.

Sin cifras concretas para extraer conclusiones definitivas, ciertas sombras se proyectan, empero, sobre este escenario de propósitos políticos: algunos compromisos presupuestarios entre las Administraciones Públicas implicadas en el desarrollo regional no se han cumplido y, por otra parte, las discrepancias que enfrentan al Gobierno autonómico (PSOE) con otros sectores de su propio partido lentifican la toma de decisiones y distrae la atención sobre los problemas más urgentes y las soluciones necesarias. En consecuencia, la reacti- 
vación económica sigue siendo, tras dos décadas de crisis, la gran asignatura pendiente, aunque no la única.

En efecto, desde el punto de vista territorial se aprecia una débil integración entre las zonas Oriental, Occidental y Central, con estructuras productivas dispares y divergentes, tendencias demográficas de signo contrario y fuertes desequilibrios infraestructurales en favor, bajo todos los supuestos, de la Zona Central. Asimismo, la articulación del espacio europeo sobre la base de las regiones y ciudades más dinámicas confirman la posición de Asturias entre las regiones periféricas, muy alejada de los grandes ejes de desarrollo continentales y nacionales. Esta realidad no está exenta de esfuerzos y empeños políticos por reactivar la región en todos los aspectos, incluida una ordenación del territorio acorde con ese objetivo general.

Está pendiente, en suma, la consagración de un modelo territorial coherente y sostenible basado en el desarrollo de sectores que propicien el crecimiento de ciudades, núcleos urbanos y áreas industriales sin marginar a las zonas rurales, creando en ellas oportunidades sobre la base de su potencial endógeno y vinculándolas al progreso de las áreas industrializadas.

\section{Bibliografía}

BENITO DEL POZO, P., (2000a): «Estrategias sectoriales y territorio: los cambios en la siderurgia asturiana», en Homenaje a Jesús García Fernández, Valladolid, Universidad de Valladolid, Departamento de Geografía (en prensa).

BENITO DEL POZO, P., (2000b): «Renovación urbana y reindustrialización. El caso de Avilés», en Industria y medio ambiente. Actas de VII Jornadas de Geografía Industrial, Alicante, Universidad de Alicante y AGE, pp. 139-148.

BENITO DEL POZO, P., (1999): «Territorio y Administración en Asturias», Polígonos, núm. 9, pp. 31-48.

BENITO DEL POZO, P., (1997): «La planificación estratégica en Asturias», en López Trigal, L. (coord.): Planeamiento urbano y estratégico. II Jornadas de Estudio y Debate Urbanos. Universidad de León, León, pp. 123-130.

BENITO DEL POZO, P., (1995): «La industria en Asturias: un declive prolongado», en Bosque, J.; Méndez, R. (eds.): Cambio industrial y desarrollo regional en España, Barcelona, Oikos-Tau, pp. 113-146.

CASTELLS, M. (dir.), (1994): Estrategias para la reindustrialización de Asturias, Madrid, Civitas.

CASTILLO, J. (DEL) ET AL., (1992): «El espacio atlántico: convergencia de periferias. Análisis de su problemática y definición de una estrategia», en AA.VV., Ejes territoriales de desarrollo. España en la Europa de los noventa, Madrid, Colegio de Economistas de Madrid, pp. 75-100.

COLINA, A., (1995): «Distribución de la actividad industrial en Asturias», en Benito del Pozo (coord.): La industria en Asturias: entre la arqueología y la innovación, Oviedo, Asociación de Geógrafos Españoles, pp. 9-25.

CUADRADO ROURA, J.R.; GARCÍA GRECIANO, B., 1995, «Integración económica y convergencia regional», en Actas XXI Reunión de Estudios Regionales. Factores de desarrollo en regiones periféricas, Vigo, Asociación de Ciencia Regional, pp. 7-20.

DE LA FUENTE, A., (1998): «Algunas reflexiones sobre el declive económico de Asturias», en Revista de Economía Asturiana, n ${ }^{\circ}$ 11, pp. 111-135. 
PASCUAL, H., (1993): Reconversión y reindustrialización en España, Valladolid, Universidad de Valladolid.

PÉREZ GARCÍA, F., (1997): «Los desequilibrios regionales en España: una revisión de la información económica (1964-1994)», en Cabero, V. y Plaza, J.I. (coords.), Cambios regionales a finales del siglo XX, Salamanca, AGE y Universidad de Salamanca, pp.4366.

PRINCIPADO DE ASTURIAS, Plan de Desarrollo Regional 2000-2003 (inédito).

PRINCIPADO DE ASTURIAS, Pacto Institucional por el Empleo, 2000-2003.

RODRÍGUEZ, F., (1999): «Alternative di industrializzazione», Sviluppo locale, vol. VI, núm. 11 , pp. 68-78.

SADEI, Datos y cifras de la economía asturiana (varios años).

VÁZQUEZ, J.A., (1994): «Asturias en el marco de las regiones atlánticas europeas», en AA.VV: Economía y empresa en Asturias, Madrid, Civitas, pp. 167-186.

VÁZQUEZ, J.A.; BENAVIDES, C., (1992): «El destino de la Cornisa Cantábrica», en AA.VV., Ejes territoriales de desarrollo. España en la Europa de los noventa, Madrid, Colegio de Economistas de Madrid, pp. 157-182.

VILLAVERDE, J., (1994): «La Cornisa Cantábrica: ejemplo de declive permanente», en Revista de Economía Asturiana, ${ }^{\circ}$ 1, pp. 93-110. 